DOI: http://dx.doi.org/10.11606/issn.1984-4867.v26i4p933-959

\title{
Olaria e Turismo Cultural: reflexões sobre o caso Alentejo-Portugal
}

Pottery and Cultural Tourism: reflections on Alentejo-Portugal case

Cerámica y Turismo Cultural: reflexiones sobre el caso Alentejo-Portugal

Jean Carlos Vieira Santos ${ }^{1}$

João Albino Silva ${ }^{2}$

\section{Resumo}

O propósito norteador deste artigo é trazer algumas reflexões sobre a produção espacial oleira do destino turístico Alentejo. Os fatos ora apresentados ressaltam que estamos em presença de um dos mais importantes elementos identitários dessas populações, a arte popular oleira. Desse modo, o encadeamento geográfico deste artigo tem como escala de análise os municípios de Évora, Redondo, Viana do Alentejo, Estremoz e a aldeia de São Pedro do Corval (Reguengos de Monsaraz). Metodologicamente, o ponto de partida de análise desta pesquisa diz respeito a um "modelo com os elementos que caracterizam as olarias e os oleiros do destino turístico Alentejo", colocando a peça de barro no centro do debate. Para o desenvolvimento deste texto, o levantamento bibliográfico, a aplicação de inquéritos, os trabalhos de campo, as conversas informais registradas em caderno de campo e a obtenção do material fotográfico foram essenciais. Por fim, o artigo mostra quem são os oleiros no destino turístico internacional, destacando o perfil desses sujeitos como resultado.

Palavras-chave: Identidade; Turismo cultural; Olaria; Alentejo; Portugal.

\begin{abstract}
The purpose of this article is to bring some reflections on the potter's spatial production from Alentejo tourist destination. The presented facts highlight that we are facing one of the major identity elements of these populations, the folk potter art. Thus, the geographical linkage of this article has the cities of Évora, Redondo, Viana do Alentejo, Estremoz and the village of São Pedro do Corval (Reguengos de Monsaraz) as an analysis scale. Methodologically, the starting point of analysis is related to a "model with elements that characterize potteries and potters from Alentejo tourism destination", setting the piece of mud at the center of debate. For the development of this text, the bibliographical study, the use of inquiries, field work, informal conversations recorded in a diary and the obtaining of photographic material were

\footnotetext{
1 Professor e Pesquisador do Curso de Geografia da Universidade Estadual de Goiás (UEG). Pós-doutorem Turismo pela Faculdade de Economia da Universidade do Algarve (UALG/Portugal). Membro do Grupo de Pesquisa CNPq: Urbana, Morfologia e Projetos (UEG). Quirinópolis-GO, Brasil. E-mail: jean.vieira@ueg.br

2 Professor catedrático da Faculdade de Economia da Universidade do Algarve (UALG). Diretor do Programa de Doutoramento em Turismo da FE da UALG. Investigador do Centro de Investigação do Espaço e das Organizações (CIEO). Algarve, Portugal. E-mail: jsilva@ualg.pt
} 
essential. Finally, the article shows who the potters are in the international tourist destination, pointing out the profile of these subjects as a result.

Keywords: Identity; Cultural tourism; Pottery; Alentejo; Portugal.

\section{Resumen}

El propósito de este artículo está en traer algunas reflexiones sobre la producción espacial alfarera del destino turístico Alentejo. Los hechos presentados resaltan que estamos frente a un de los principales elementos de identidad de estas poblaciones, la arte popular alfarera. Por lo tanto, la vinculación geográfica de este artículo tiene como escala de análisis los municipios de Évora, Redondo, Viana do Alentejo, Estremoz y el pueblo de São Pedro do Corval (Reguengos de Monsaraz). Metodológicamente el punto de partida del análisis de este trabajo es el "modelo con elementos que caracterizan la alfarería y los alfareros del destino turístico Alentejo", colocando la pieza de arcilla en el centro de debate. Para el desarrollo de este texto fueron importantes el estudio bibliográfico, la utilización de averiguaciones, el trabajo de campo, las conversaciones informales registradas en un diario y la obtención de material fotográfico. Por último, el artículo muestra quien son los alfareros en el destino turístico internacional, presentando un perfil de estos sujetos como resultado.

Palabras-clave: Identidad; Turismo cultural; Cerámica; Alentejo; Portugal.

\section{Introdução}

O propósito norteador deste artigo é trazer algumas reflexões sobre a produção espacial oleira, o desenvolvimento e a promoção dessa arte popular em cidades pequenas que formam o destino turístico Alentejo (Portugal). Os fatos aqui apresentados mostram que a arte popular oleira é um dos mais importantes elementos identitários dessas populações e, mesmo para além de sua salvaguarda, é necessário colocá-la como um instrumento a serviço do desenvolvimento dessa região, nomeadamente por meio da promoção de um turismo cultural - isso quer dizer que as políticas públicas devem articular as duas dimensões.

Hoje é possível afirmar, explicitamente, que a arte popular oleira no Sul de Portugal é, por direito próprio, um símbolo vivo da história e tradição de sujeitos que desenvolvem (e desenvolveram) seus modos de vida contemporâneos em municípios da região Alentejo, ao manter raízes, conteúdos e densidades de um saber fazer popular com o barro que ainda se revela como importante para a identidade cultural e social de suas populações. De acordo com Conde (2013): 
A natureza dos solos, aliada ao clima seco, propiciaram o surgir no Alentejo, no dizer de Orlando Ribeiro, da Civilização do Barro. Desde os tempos préhistóricos que o vasilhame de barro se encontra ligado ao viver alentejano, tanto nas tarefas agrícolas e suas derivadas, como na vida doméstica e na vida social. Se aos romanos devemos o sentido prático do aproveitamento das riquezas naturais, e na região alentejana o barro brindou diversas zonas com a sua presença, a herança árabe, de um povo acostumado a tratar esta matéria com um carinho muito especial, porque aliada à preciosa conservação da água ou ao seu transporte em zonas onde era rara, em grande parte completaria $\mathrm{o}$ patrimônio cerâmico que herdamos (CONDE, 2013, p. 7).

É necessário, portanto, assinalar que o Alentejo possui um relevante patrimônio cultural oleiro, uma arte popular tradicional que também é contemporânea, reflexo de um conhecimento que se mantém ao longo do tempo e espaço. A atual existência da cerâmica alentejana “[...] explica-se facilmente pela presença dos depósitos argilosos" (MAUSS, 1972, p. 47) e pela "[...] riqueza e grande variedade das argilas portuguesas" (LEPIERRE, 1912, p. 20), assim como de outros recursos naturais e sociais.

Nesse contexto, não se pode esquecer o papel de seus sujeitos oleiros, pois o mérito é, sem dúvida, desses artesãos do barro, cuja aptidão tradicional revela grande maestria técnica e notabilíssimo "[...] sentido da forma, aliado ao bom critério na ornamentação dos objetos. Sem projetos desenhados e com a escola da vida passada empiricamente de geração em geração, ele reproduz belas peças rústicas, ou recria peças mais artísticas" (GANCHO, 2000, p. 14). Vale ressaltar que o segundo modelo de peça traz consigo um domínio da arte com elementos de inspiração erudita, fortalecendo o desenvolvimento do turismo cultural regional.

Produzir este artigo científico seria reconhecer uma afortunada tarefa de aprofundar na cultura oleira das cidades pequenas ${ }^{3}$ do Alto Alentejo, com um olhar voltado a uma nova discussão, em "[...] redescobrir os pequenos/grandes mundos do nosso cotidiano e lançar um renovado olhar sobre os laços que todos os homens, a cada homem, entretecem com o espaço onde vivem, trabalham, descansam" (SANTOS, 2006, p. 21). É, de fato, buscar compreender as diferentes direções espaciais da cerâmica alentejana que:

$\mathrm{Na}$ olaria das diferentes regiões, de norte a sul, está presente, na variedade, a criatividade cultural de nossa gente. A olaria é o retrato das necessidades, ideias e espírito de inversão do povo de cada região. [...] tradição tão diversa, na sua arte e poesia (NUNO/CÂMARA MUNICIPAL DE ALMADA, 2002, p. 12).

\footnotetext{
${ }^{3}$ Os municípios de Redondo, Viana do Alentejo, Estremoz e a aldeia de São Pedro do Corval (Reguengos de Monsaraz) têm menos de 15 mil habitantes; por isso, serão aqui denominados como cidades pequenas.
} 
Quanto à escala de análise deste trabalho, é pertinente citar Ribeiro (1986, p. 151), um especialista dedicado ao estudo geográfico português, que caracteriza o Alentejo como "[...] a mais vasta e monótona unidade natural do nosso território”. Há originalidade dessa região que, geograficamente, reside tanto na imensidão da terra lisa ou apenas quebrada em frouxas ondulações:

[...] como no clima, a que a falta de centros de condensação da humidade do ar apaga todos os caracteres oceânicos. $\mathrm{O}$ mais provém daí. Até o fim do século XIX, a região era uma charneca entrecortada de tractos de seara com pousios de muitos anos. Entretanto, arrotearam-se terras boas e más. Limparam-se e espaçaram-se as árvores do montado, que viviam afogadas no matagal de estevas e medronheiros; plantaram-se olivais; parcelaram-se as herdades em foros; multiplicaram-se as courelas, e, juntamente, a policultura e a dispersão. A despeito dessas transformações, a lavoura extensiva predomina (RIBEIRO, 1986, p. 157-158).

Ainda na obra de Ribeiro (1986, p. 160-161), Évora, a capital dessa região, é a cidade mais bela de Portugal, porque o seu desenvolvimento recente se fez extramuros e preservou o núcleo tradicional: "Évora ilustra particularmente bem a tendência das cidades portuguesas se estruturarem em torno de praças múltiplas, umas dentro e outras fora do circuito fortificado". Nesse entremeio, a valorização dos circuitos fortificados é uma característica comum às cidades pequenas portuguesas investigadas neste trabalho.

Para as cidades ora pesquisadas, o turismo cultural e as outras atividades de turismo representam uma alternativa socioeconômica, no âmbito da cidadania, de geração de emprego e fonte de renda; da promoção do desenvolvimento econômico e cultural nas bases local e regional; e da conservação de recursos "[...] históricos e patrimoniais que contribuem para a criação e desenvolvimento de produtos turísticos diversificados, respondendo a diversos tipos de motivações e a mercados cada vez mais alargados" (COSTA et al., 2014, p. 13).

É nesse enquadramento teórico que se coloca o turismo cultural como um fenômeno civilizacional suportado por cultura, história, povos, língua, trabalho artesanal e um sistema de símbolos e valores, mas que, em suas contradições, envolve a produção e consumo. Desse modo, o turismo deve ser visto "[...] no âmbito de um paradigma moderno de gestão e planejamento de pessoas, do patrimônio, da cultura" (COSTA et al., 2014, p. 13). 
Segundo Barretto (2007, p. 87-88), no turismo cultural o principal atrativo é a "“[...] cultura humana, que pode ser a história, o cotidiano, o artesanato ou qualquer dos aspectos abrangidos pelo conceito de cultura". Para a autora, esse tipo de turismo é uma incursão "[...] personalizada em outros locais e culturas para aprender sobre as pessoas, seus estilos de vida, seu legado e sua arte, características que devem ser mostradas de uma forma tal que represente genuinamente essas culturas e seus contextos históricos" (Idem).

Medina e Santamarina (2004, p. 64), por exemplo, dizem que o turismo cultural:

Responsablemente concebido y realizado, el turismo cultural es, entre muchas otras posibles interpretaciones, incluyendo las económicas, un puente de comunicación y entendimiento entre culturas y pueblos, un factor de comprensión directa de la diversidad cultural para las personas, visitantes y visitados. En la conceptualización cubana, [...] integra operacionalmente para el visitante - los componentes del paisaje cultural.

De acordo com Cunha (2001, p. 49), pode-se afirmar que o turismo cultural, literalmente, se define pelas viagens provocadas pelo desejo de ver coisas novas, de aumentar "[...] os conhecimentos, conhecer as particularidades e os hábitos doutros povos, conhecer civilizações e culturas diferentes, do passado e do presente, ou ainda a satisfação de necessidades espirituais".

Nesse sentido, a obra de Fayos-Solà e Jafari (2009, p. 160) ajuda a compreender que o turismo cultural deve "[...] respetar la autenticidad sociocultural de las comunidades anfitrionas, conservar sus activos culturales, arquitectónicos y vivos y sus valores tradicionales, y contribuir al entendimiento y a la tolerancia interculturales". É possível, porquanto, pensar que o sujeito que interessa ao turismo cultural é também um ser de cultura, pois o que sabe fazer e as motivações para isso ele aprende a partir do que o rodeia. A cultura assim adquirida é feita de elementos díspares, às vezes contraditórios (CLAVAL, 2008).

Por fim, o encadeamento geográfico deste artigo tem Alentejo dentro da escala de análise, com um especial olhar para os municípios de Redondo, Viana do Alentejo, Estremoz e a região de São Pedro do Corval (Reguengos de Monsaraz), localizados no Alto Alentejo. A compreensão dos sistemas de produção, comercialização e apoio à atividade oleira nesses locais propiciará a análise de uma arte popular, realizada predominantemente em unidades produtivas do tipo familiar, o qual continua, de algum modo, a satisfazer as necessidades de moradores e turistas que chegam a esses destinos. 


\section{Materiais e Métodos}

Metodologicamente, este trabalho tem como ponto de partida de análise o "Modelo com os elementos que caracterizam as olarias e oleiros do destino turístico Alentejo" (Figura 1). Coloca-se a peça de barro como centro do debate e busca-se sublinhar o olhar para as peças contextualizadas, como se elas fossem o espelho das comunidades e, por isso, da identidade, tornando-se também um importante instrumento de promoção do turismo cultural regional.

Ao especificar a realidade estudada, pode-se afirmar que as identidades são elaboradas ou se reforçam pelas mãos criativas de artistas oleiros do lugar, apresentando em suas obras uma enorme relação de afetividade e pertencimento com a região, as paisagens e os territórios do Alto Alentejo. Ainda sobre o modelo, este nos possibilitou avançar no diálogo a partir da realidade de momento e permitiu estruturar os resultados da análise e do inquérito aplicado.

A partir da ideia central apresentada, é possível afirmar que existem lacunas de estudos que abranjam, a nível nacional e regional, o levantamento e a caracterização de algumas abordagens sobre a olaria das cidades pequenas do Alto Alentejo e sua relação de existência associada às atividades de turismo. É uma discussão que compartilha uma série de temas comuns, bem como diversas temáticas abrangentes e divergentes. Diante dessa discussão sobre olaria e turismo, é interessante observar que:

El turismo, fenómeno de naturaleza compleja y concebido como conjunto de actividades diversas, ha constituido y constituye un factor de transformación $\mathrm{y}$ un componente estructural de nuestra sociedad. Su complejidad y diversidad se concentran en distintas manifestaciones (sociales, económicas, geográficas, políticas...) y por ello ha sido y es objeto de estudio por parte de diversas disciplinas científicas (economía, geografía, sociología, antropología, arquitectura y urbanismo...), que han abordado su problemática, y ha sido y es objeto de atención por parte de entidades, instituciones y organismos, tanto de carácter público como privado (VERA; PALOMEQUE; MARCHENA; ANFON, 1997, p. 21). 


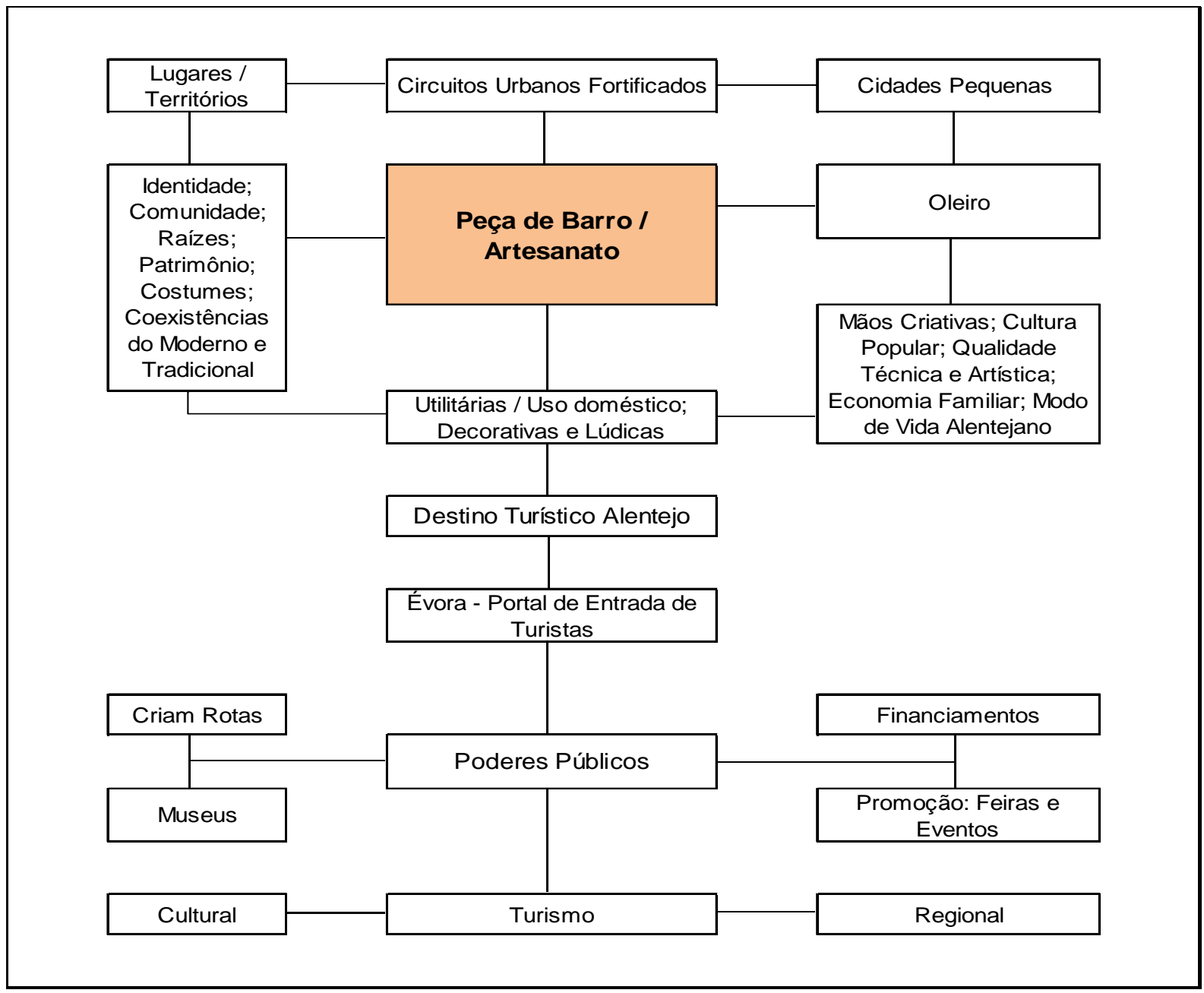

Figura 1: Elementos que caracterizam as olarias e oleiros do destino turístico Alentejo.

Fonte: Elaboração dos autores.

Com o intuito de compreender o trecho descrito anteriormente, recorre-se a Gancho (2000, p. 19), que esclarece em sua obra que a cerâmica, assim como a "[...] azulejaria, a faiança e a porcelana, têm merecido prestigiada atenção de parte dos investigadores", constituindo um relevante contributo para a compreensão e contextualização não só nos campos da Geografia, Economia e Turismo, como em áreas afins. Neste estudo:

[...] los enfoques son formas de incorporar la dimensión temporal al análisis social, permite ubicar el contexto, la duración temporal, la orientación y el sentido de las acciones sociales. A través de las temporalidades es posible analizar la continuidad o duración efímera de los acontecimientos sociales, además, éstas muestran cómo los distintos acontecimientos transcurren bajo ritmos diferentes, dando pauta para que el estudioso de la realidad social pueda organizar el pasado (HERNÁNDEZ, 2013, p. 36). 
A análise documental e bibliográfica apresentadas neste artigo está orientada para o levantamento que caracterize as olarias e turismo cultural, bem como a arte popular, a enorme força artística com o barro, os sujeitos e atores oleiros, o trabalho e os traços genuínos de verdadeiras obras de arte fincadas em residências e comércios de cidades pequenas, pois: "Los componentes culturales constituyen, a priori, recursos turísticos potenciales, que interviene en los procesos de producción consumo [...]" (VERA et al., 1997, p. 64).

Recorremos aos serviços das bibliotecas da Universidade do Algarve, da Universidade de Coimbra e da Universidade de Évora para a realização da pesquisa documental e bibliográfica, etapa que foi fundamental para a construção teórica. Quanto aos instrumentos utilizados, após a pesquisa bibliográfica, foi possível desenhar um questionário, estruturado em três blocos, que permitisse uma aproximação dos pesquisadores com a realidade encontrada no Sul de Portugal (Alto Alentejo).

O primeiro bloco traz informações sobre a "Caracterização do Oleiro"; o segundo evidencia a "Caracterização das Relações Olaria-Promoção-Turismo"; e o terceiro expõe a "Caracterização das Formas de Comercialização". Do ponto de vista metodológico, o instrumento utilizado propõe nomeadamente um modelo de inquérito adaptado à realidade da região Alto Alentejo, com vistas a preencher algumas deficiências de conhecimento sobre essa paisagem. Na tentativa de interpretar essas lacunas, no tocante ao:

[...] inquérito, a escolha das variáveis a ter em conta para os estudos e medições em causa procurou dar resposta à necessidade de conhecer a população-alvo, estabelecer eventuais relações de causalidade e determinar as principais tendências, em termos de padrões espaciais. A informação acerca do grupo social que definimos foi processada de modo a tornar quantificáveis os resultados obtidos ou, pelo menos, nos casos em que pela sua própria natureza tal seja inviável, passíveis de interpretação e sistematização (SANTOS, 2006, p. 41-42).

Os inquéritos foram realizados num universo de pesquisa de 23 sujeitos, proprietários das olarias existentes na região do Alto Alentejo. Este estudo contou, ainda, com o trabalho de campo que proporcionou uma compreensão melhor das dinâmicas espaciais da escala de análise. Esse momento possibilitou a observação direta; a conversa informal, registrada em caderno de campo; e a obtenção do material fotográfico que foi posteriormente catalogado.

É importante ressaltar que esta investigação se deu a partir da mescla dos métodos quantitativo e qualitativo, tendo o trabalho oleiro como representante da arte popular 
portuguesa em um destino turístico. Não se propõe trazer uma definição ou uma discussão mais profunda sobre a arte popular, mas apresentar as formas tradicionais e contemporâneas do artesanato que estão ligadas estreitamente aos sujeitos residentes em pequenas cidades portuguesas, ao seu modo de vida e hábitat, à economia familiar e às tradições culturais que foram transmitidas de geração para geração.

\section{O Destino Turístico Alentejo no Sul de Portugal: a olaria no contexto regional}

O destino turístico Alentejo é uma região de recepção e acolhimento que oferece vários produtos turísticos totais e diversos atrativos. É um cenário que proporciona uma gama de experiências aos visitantes que chegam do exterior ou do próprio país. Do ponto de vista da oferta, o destino possui um conjunto de requisitos essenciais, como: acessibilidade/estradas turísticas sinalizadas, condições de alojamento, atividade de recreio, lazer, desporto, cultura, entre outros capazes de preencher os tempos livres dos turistas de acordo com as suas motivações. Isso faz dizer que:

The recognition of the importance of the tourism sector to national economies, the acknowledged concern with destination competitiveness, the recognition of the strategic role of quality improvement for the competitive positioning of tourism products, not to mention the challenge itself of breaking new ground in a knowledge area, are the main reasons for choosing this research theme. The core research objective is to argue that it is possible to quantify the quality status of destinations with scientific accuracy, and to present an assessment methodology that can effectively help managers in the decision-making process (MENDES; SILVA; FERREIRA, 2010, p. 31).

Essa região no Sul de Portugal possui um número de elementos básicos que atraem os visitantes e que satisfazem suas necessidades durante a permanência e as visitações: “[...] possui um rico patrimônio natural e cultural e dispõe de condições para o desenvolvimento de produtos turísticos susceptíveis de atenuarem a sazonalidade característica do setor" (MINISTÉRIO DA ECONOMIA, 2002, p. 120).

Capital e principal cidade regional, Évora é geograficamente em sua essência o ponto de articulação e partida dos turistas que chegam ao Alto Alentejo, como mostra a Figura 1. Temse, por certo, que é a partir desse núcleo urbano que um elevado número de sujeitos visitantes chegam às outras cidades da região, percorrendo diferentes lugares, territórios, paisagens e destinos, que apesar de uma considerada distancia entre atrações, essa cidade não perde suas 
características de núcleo receptor e dispersor, impondo normas de mobilidade na regionalização do turismo no sul de Portugal.

De fato, Évora (Figura 2) não anula os locais urbanos menores; pelo contrário, criam-se indissociavelmente meios e possibilidades de apresentar aos turistas o rico patrimônio cultural, social e econômico regional, colocando esse cenário como um espaço relacional de sujeitos que nele vivem e reagem. Nesse aspecto, configura-se como lócus relacional a existência dos órgãos públicos de turismo, a exemplo da Entidade Regional de Turismo do Alentejo e das empresas privadas.

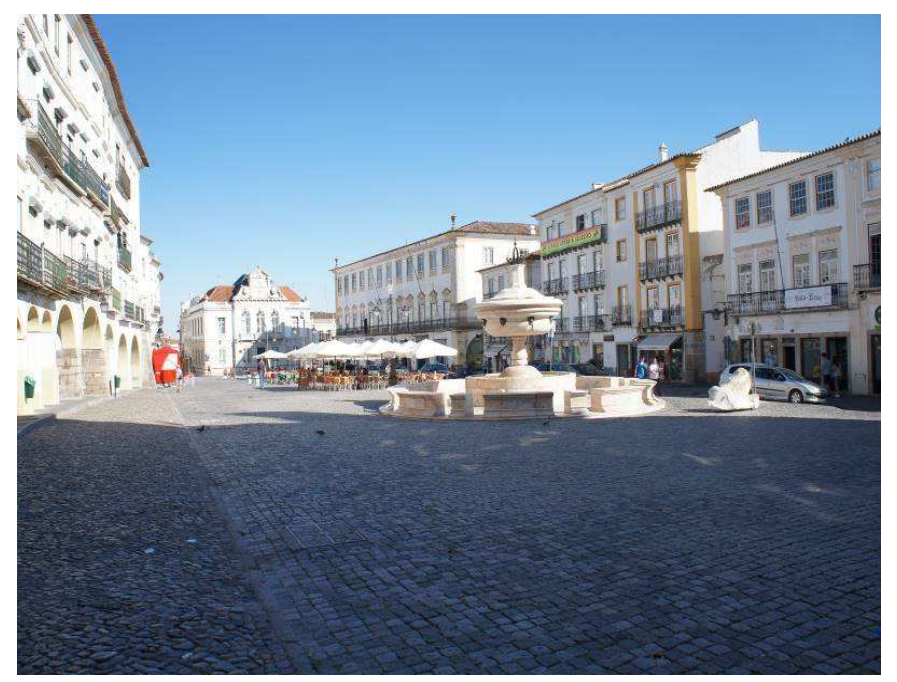

Figura 2: Região central de Évora, onde se concentra um grande fluxo de turistas e moradores. Fonte: Elaboração dos autores.

A sua força no destino se assenta não só no título de Patrimônio da Humanidade, mas nos recursos tradicionais-identitários e em produtos turísticos relacionados com o ambiente e os patrimônios paisagístico e histórico, o que proporciona circuitos diversificados, articula um interior de vida social tradicional e contemporânea, e promove o encontro de várias localidades cuja "[...] história, cultura e patrimônio justificam que sejam incluídas na oferta turística regional, para desse modo desempenharem um papel importante no desenvolvimento do Alentejo" (MINISTÉRIO DA ECONOMIA, 2002, p. 120). De uma forma ou de outra, o que se percebe é que: 
Los factores culturales, [...] responden a la acepción de patrimonio cultural y de cultura inmaterial. Y, si atendemos a las tipologías ya tradicionales, se trata de los recursos litom (restos arqueológicos, monumentos históricos, museos) y de los recursos antropom (artesanía, folclore, fiestas) (VERA; PALOMEQUE; MARCHENA; ANFON, 1997, p. 69).

De modo particular, as questões que marcam a importância de Évora na escala do turismo regional descrita nesta parte do presente artigo têm como objetivo destacar um processo de regionalização que fortaleceu formas, cenários, espaços e personagens/sujeitos/atores que dão o tom sociocultural dos conteúdos oleiros nas cidades de Estremoz, Viana do Alentejo, Redondo e São Pedro do Corval (aldeia pertencente a Reguengos de Monsaraz) (Figura 3). Tal processo incorpora no fazer-saber-viver de urbanidades pequenas relações sociais, econômicas e culturais, em que "[...] a produção de cerâmica utilitária no Alto Alentejo é anterior à civilização cristã” (BORRALHO, 1993, p. 21), ou seja, é uma arte e ofício que persiste no tempo e espaço.

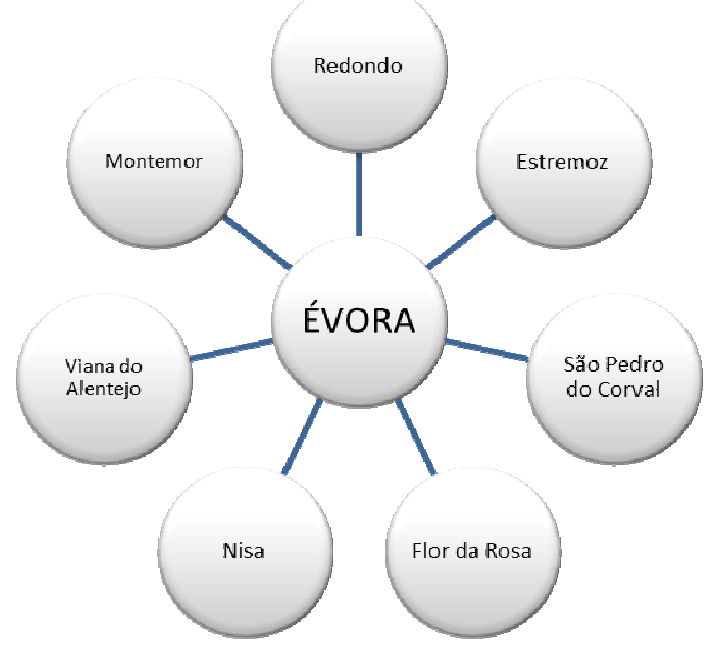

Figura 3: Évora e os principais centros oleiros antigos e contemporâneos do Alto Alentejo (Portugal).

Fonte: Elaboração dos autores.

Na contramão do sistema globalizado e virtual, essas cidades e a aldeia de Corval são, na essência de um contexto particular regional, espaços da técnica e da lógica da olaria. Isso não quer dizer que tais localidades diferenciadas pela presença de trabalhadores artesãos do barro ou barrística estão excluídas do mundo e das relações globais, pois se abrem para o mundo a 
partir da mídia, da internet, dos circuitos e das redes de turismo revelando identidade e raízes, além de promover os movimentos de produção e consumo.

Diante dessas observações, considera-se pertinente sublinhar que, nas cidades do Alto Alentejo, as olarias podem ser compreendidas como uma lógica de formas e ideias espontâneas construídas ao longo do tempo e espaço e influenciadas pela raiz-cultural do lugar com seus costumes, modos de vida e aceitação do turismo cultural como uma possibilidade comercial e de aumento na circulação de dinheiro nos municípios e aldeias, o que configura um novo cenário regional e mantém tradições territoriais para novos usos. É importante ressaltar que:

Os lugares mais afamados na olaria alentejana são Nisa e Flor da Rosa, do distrito de Portalegre, Estremoz, Redondo, São Pedro do Corval (Reguengos de Monsaraz) e Viana do Alentejo, no distrito de Évora e Beringel em Beja. Porém ainda na primeira metade do século (século XX) funcionavam olarias em Castelo de Vide, Campo Maior, Elvas, Ponte de Sôr, Évora, Almodovar, Castro Verde, entre outras. Era vulgar encontrar em qualquer vila alentejana a Rua da Olaria ou dos Oleiros e os velhos fornos onde se cozia toda a espécie de obra. Fazia-se telha comum, o ladrilho, o tijolo mais conhecido por lambaz e baldoza. Muita desta nomenclatura tem raiz árabe, pois o muçulmano, mais do que o romano, desenvolveu por toda a região a indústria da cerâmica, arte em que foi considerado mestre (INSTITUTO DO EMPREGO E FORMAÇÃO PROFISSIONAL/DELEGAÇÃO REGIONAL DO ALENTEJO, 2000, p. 31).

Em 1968, Parvaux, ao investigar as olarias do Alto Alentejo, escreve em sua obra que já não existia fábrica de louça de barro em Montemor. Em destaque, tem-se o desaparecimento das relações sociais, culturais e de produção da arte popular oleira tradicional nessa cidade alentejana. Isso faz pensar que na olaria também há características do viver alentejano, um patrimônio que privilegia o saber-fazer que se consuma no surgir de peças (Figura 4) com as seguintes características: utilitárias para a prática cotidiana, lúdicas e decorativas. 


\section{TURISMO EM ANÁLISE}

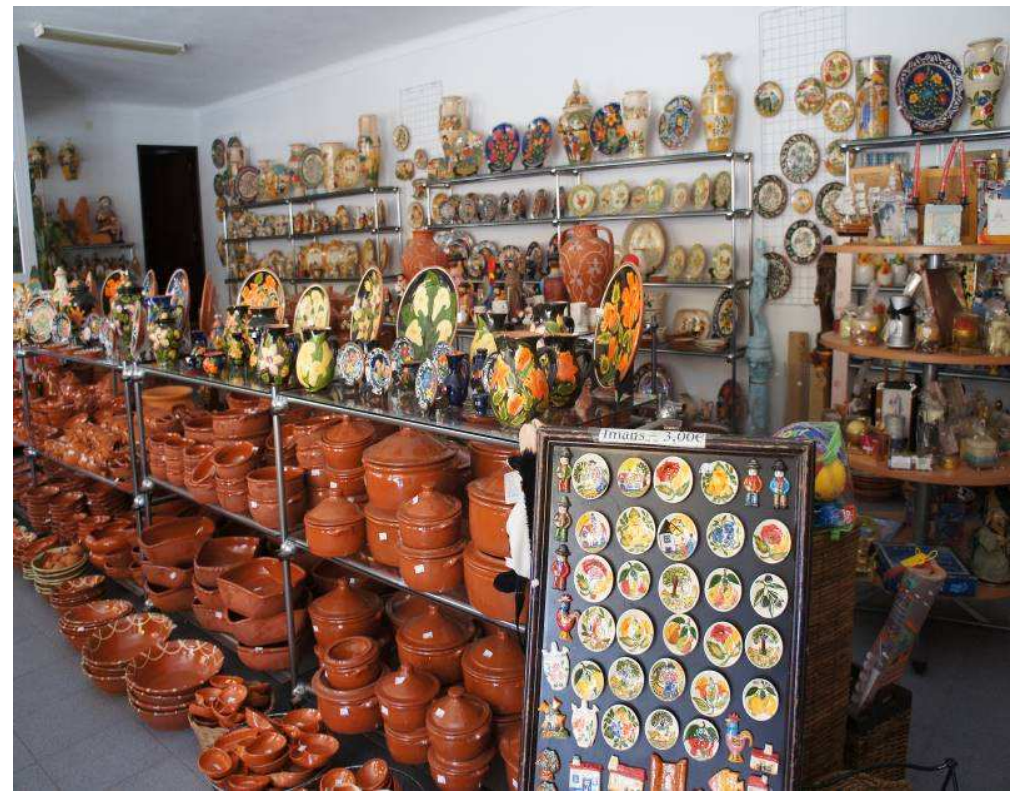

Figura 4: Peças em comércio anexo à olaria na cidade de Redondo, que atualmente é um dos principais centros oleiros do Alentejo e de Portugal.

Fonte: Elaboração dos autores.

Tais peças de barro simbolizam a cultura material no Alentejo. Os artesãos continuam a produzir, em seus comércios e residências, peças que reforçam uma cultura valiosa, uma arte com alma, com alicerces que representam as tradições dessa paisagem, valorizando suas raízes e revalorizando a identidade regional. Esse patrimônio de saber e arte é uma verdadeira marca que diferencia tais territórios de outros espalhados pelo país.

\section{Inquérito como Ferramenta de Investigação: conhecendo os sujeitos oleiros}

Interessa aqui, sobretudo, dar uma ideia de quem são os sujeitos oleiros contemporâneos do Alto Alentejo que, com suas mãos criativas, dão forma às argilas e criam peças que são o centro deste debate, como apresentado na Figura 1 - nesse caso, apresenta-se o método quantitativo do trabalho, que tem entre seus objetivos ilustrar o universo estudado. $\mathrm{Na}$ caracterização dos inquiridos, quanto ao sexo, é possível dizer que $69,5 \%$ são do sexo masculino e $30,5 \%$, do feminino.

De acordo com dados de campo colhidos na Entidade Regional de Turismo, nas Câmaras Municipais e Juntas de Freguesia, até 2014 existiam 37 olarias comerciais em Redondo, 
Estremoz, São Pedro do Corval (Reguengos de Mosaraz) e Viana do Alentejo, sem contabilizar os sujeitos que trabalham em suas residências.

Desse universo foram obtidas informações por meio de inquérito em 23 olarias, com maior número em São Pedro do Corval, município de Reguengos de Monsaraz. O Gráfico 1 mostra o local de nascimento dos atuais oleiros da região, evidenciando que o maior número de sujeitos são oriundos de Redondo e São Pedro do Corval, ainda considerados os maiores centros urbanos oleiros do Alto Alentejo em Portugal.

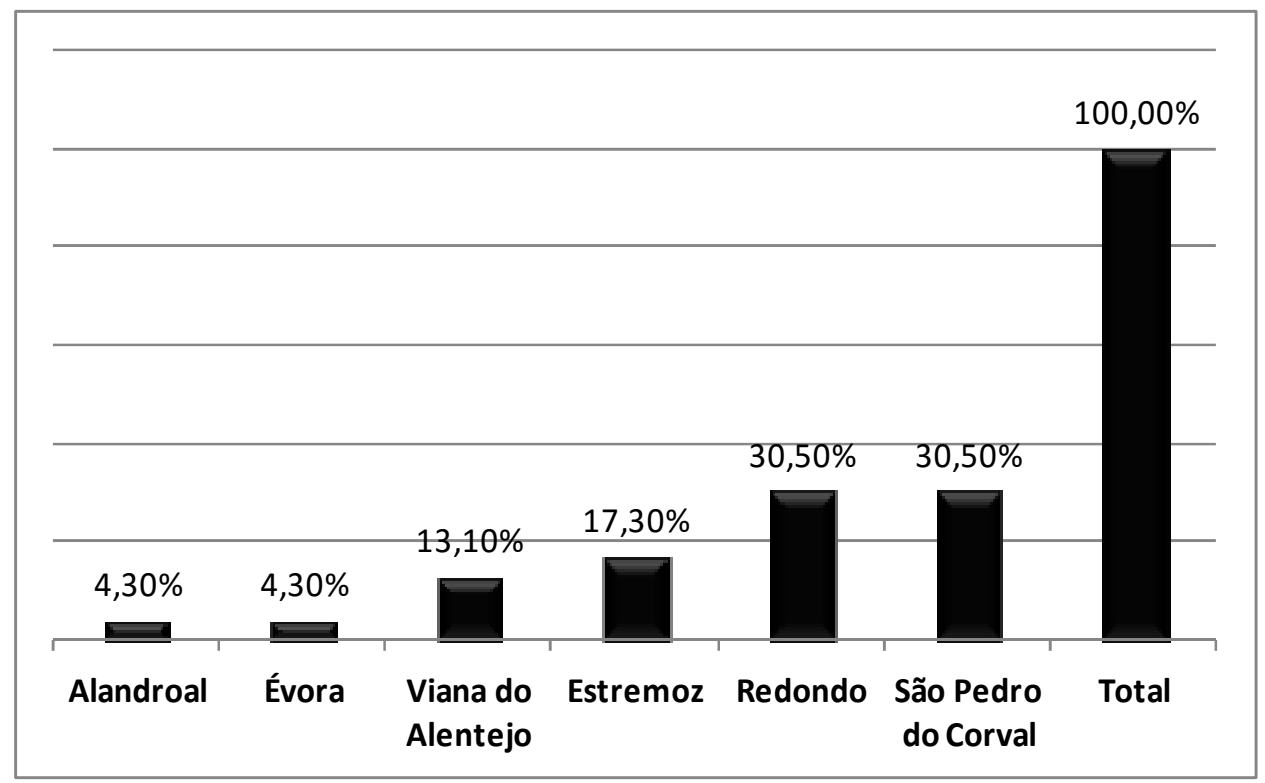

Gráfico 1: Local de nascimento dos oleiros do Alentejo

Fonte: Elaboração dos autores.

Enquanto isso, as informações do Gráfico 2 destacam um envelhecimento desses trabalhadores, pois são poucos os artesãos mais jovens que querem aprender o ofício oleiro e produzir. Segundo Gancho (2000, p. 201):

Muito preocupante é o facto da média de idade dos rodistas ser de cerca de cinquenta e quatro anos, não existindo aprendizes de ofício. São raros os mestres oleiros e suas esposas, que não descendem, há várias gerações de famílias ligadas ao fabrico de cerâmica. De modo geral os seus filhos/as possuem cursos médios ou superiores, sendo poucos os que se tem dedicado à cerâmica.

Tal autor deixa a entender que o envelhecimento do oleiro é um fato. Mesmo com os números apresentados, um oleiro entrevistado durante os trabalhos de campo vê a atual olaria do Alto 
Alentejo muito diferente do passado, e, apesar da elevada faixa etária desses profissionais, ele opina que as mudanças não deixaram de ocorrer:

A olaria está muito mais moderna, a loiça tem mais qualidade, entretanto deixou-se de fazer parte das coisas que se faziam, como os cântaros que as pessoas guardavam água. Ficava água muito fresquinha, isso praticamente desapareceu. É como digo, hoje temos o turismo, pois a loiça de barro é feita para o turista. Quando começaram a vender a loiça pintada para o turista, tinha mais de 200 senhoras em Corval a pintar a loiça da terra (ENTREVISTA INFORMAL DE CAMPO, OLEIRO DE SÃO PEDRO DO CORVAL, 2014).

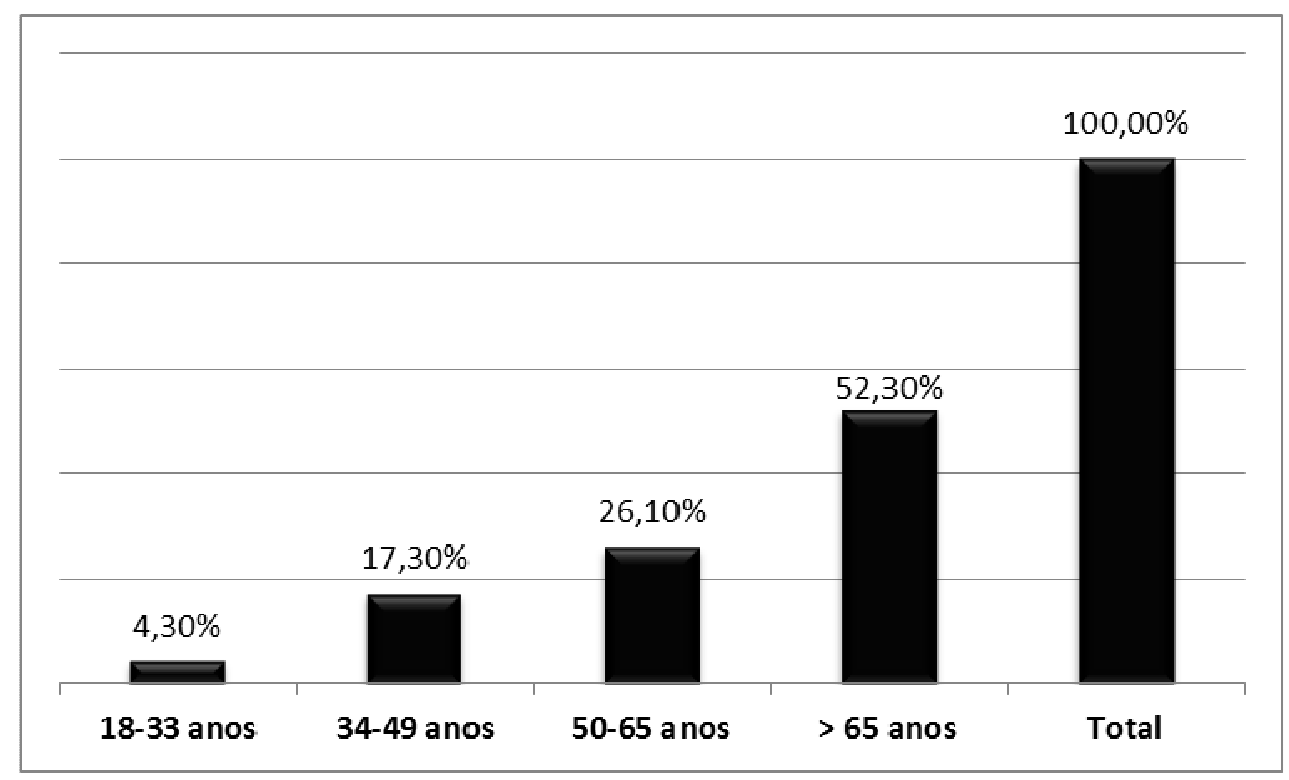

Gráfico 2: Faixa etária dos oleiros pesquisados

Fonte: Elaboração dos autores.

Nesse contexto, o Gráfico 3 apresenta que a maioria dos inquiridos $(69,6 \%)$ são casados. No que tange, às habilitações literárias (Gráfico 4) desses indivíduos, destaca-se o primeiro ciclo de ensino, com 43,7\%. Borralho (1993), em sua obra, lembra que na última década do século XX a maioria dos oleiros de Estremoz se divide pelo ensino básico primário e pelo ensino secundário unificado, diferenciando em parte dos resultados encontrados e apresentados no Gráfico 4. 


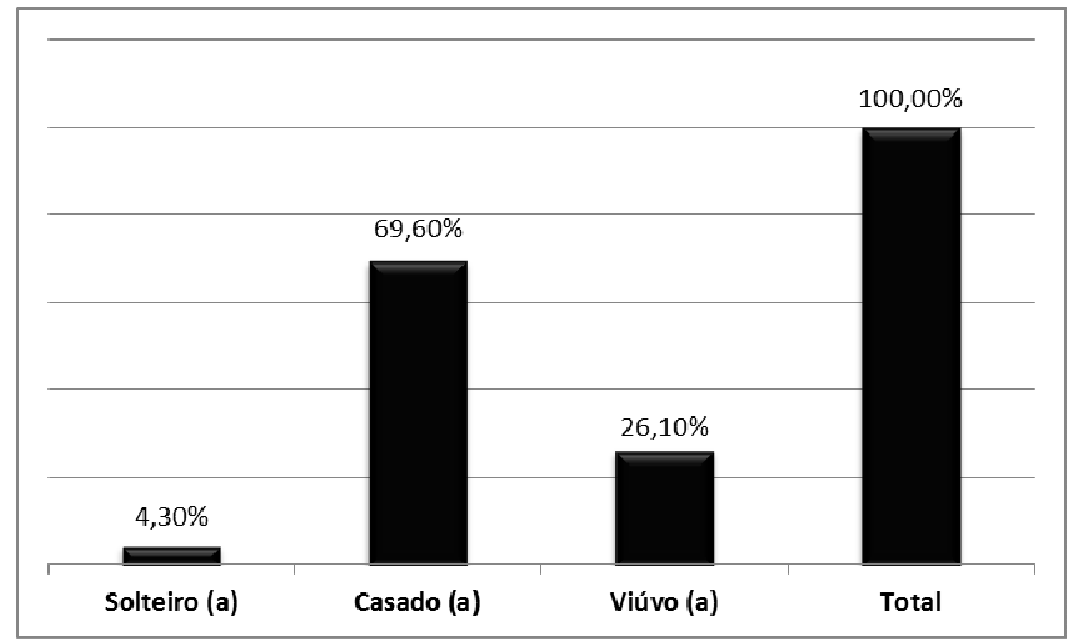

Gráfico 3: Estado civil dos oleiros do Alentejo

Fonte: Elaboração dos autores.

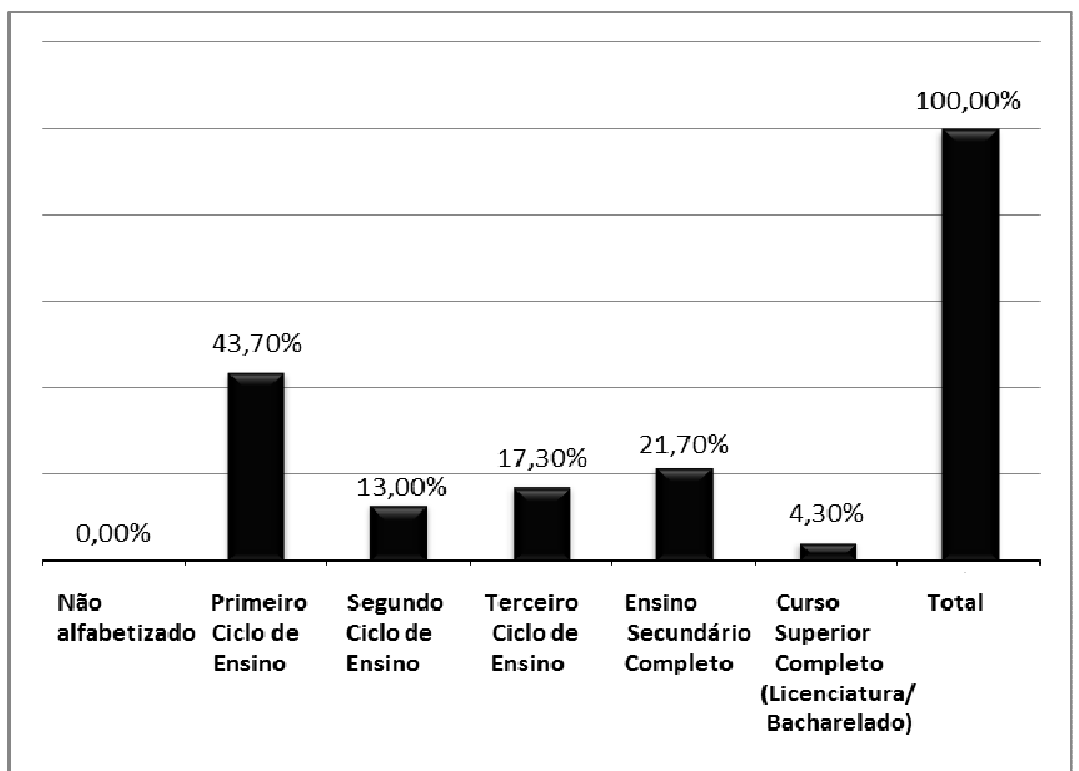

Gráfico 4: Formação escolar dos oleiros

Fonte: Elaboração dos autores.

A fim de reforçar a formação profissional dos sujeitos oleiros, buscou-se conhecer como ocorreu o processo de aprendizagem da profissão. O resultado dessa questão (Gráfico 5) mostra que a maioria $(56,6 \%)$ aprendeu o ofício com familiares. Desse universo de 56,6\% sujeitos artesãos que foram aprendizes do ofício com parentes, $69,3 \%$ obtiveram conhecimento com os pais, 15,3\%, com esposos, 7,7\%, com o avô e outros 7,7\%, com tios. Esses números mostram a força dos laços consanguíneos no fortalecimento da economia familiar local e regional. 


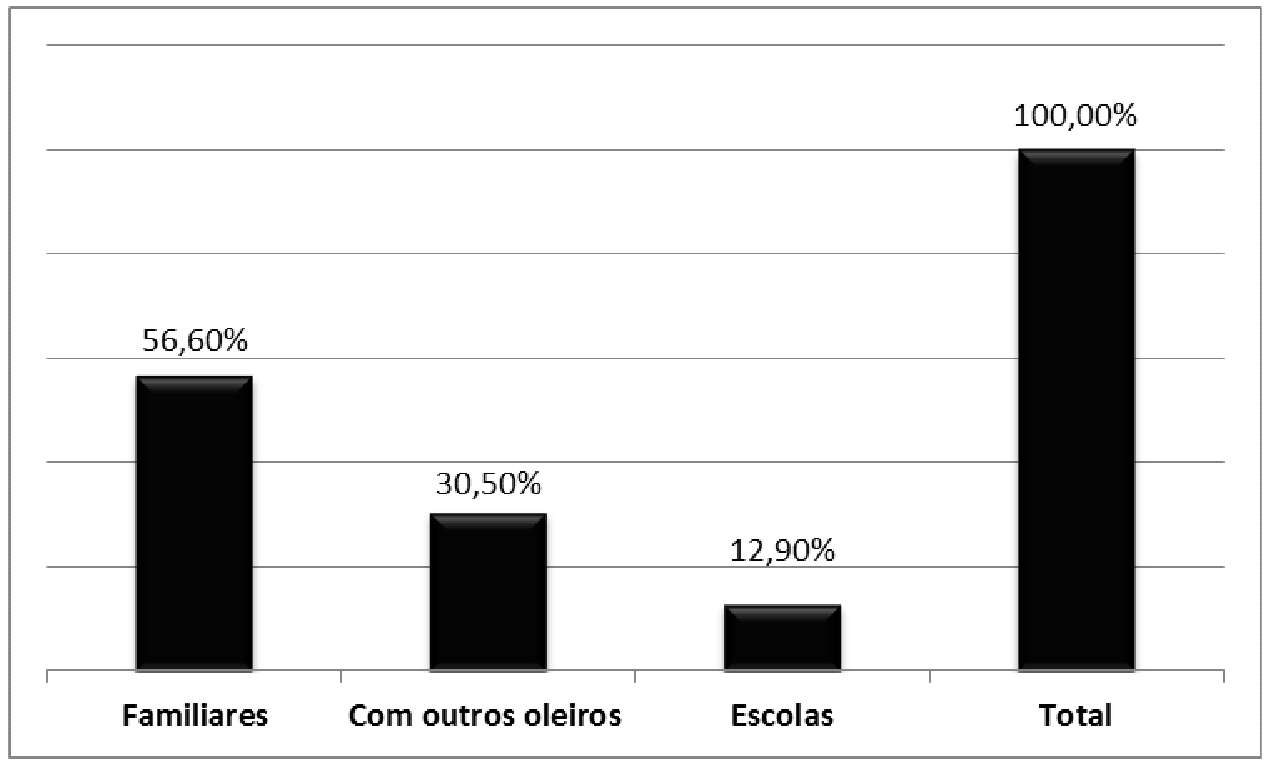

Gráfico 5: Aprendizagem do ofício oleiro

Fonte: Elaboração dos autores.

Na tentativa de interpretar os significados de existência desse ofício tradicional e popular, nas primeiras décadas do século XXI, optou-se por saber quanto tempo os inquiridos trabalham com o artesanato oleiro (Gráfico 6). O maior grupo (78,5\%) trabalha com esse ofício ha mais de 30 anos. Como já citado, os dados demonstram uma falta de interesse dos jovens em aprender a olaria e uma necessidade absoluta de renovação para que essa tradição alentejana não desapareça.

Procurou-se verificar a quantidade de sujeitos que trabalham em cada olaria, o que se considera uma necessidade para demonstrar o poder de geração de emprego e renda, uma vez que não foi encontrado nenhum trabalho de investigação que tenha abordado esse assunto. Em 35,1\% das olarias, há apenas um trabalhador, que também é o proprietário do negócio. Com dois trabalhadores, normalmente esposa e esposo, teve-se o universo de 30,5\%, corroborando uma perspectiva de base familiar.

Ainda no tocante ao número de trabalhadores nas olarias, foram encontrados $8,6 \%$ dos estabelecimentos oleiros com três pessoas executando seu labor. Deve-se reconhecer que esse universo revela olarias que têm em sua base o trabalho familiar: 8,6\% empregam quatro pessoas; $8,6 \%$, cinco funcionários; e outras $8,6 \%$, dez colaboradores. 
De fato, a pintura das cerâmicas é a principal tarefa executada pelos sujeitos nas empresas oleiras que mais empregam, sendo que há nesse terreno um maior número de empregos para o sexo feminino, com 51,6\%, e 48,4\%, para o grupo masculino. Já no que concerne à promoção ou divulgação de cada olaria, as informações apontam que 69,7\% disseram contar com o apoio das Câmaras Municipais, da Junta de Freguesia de São Pedro do Corval e da Entidade Regional de Turismo, e 30,3\% afirmaram que não recebem nenhum apoio.

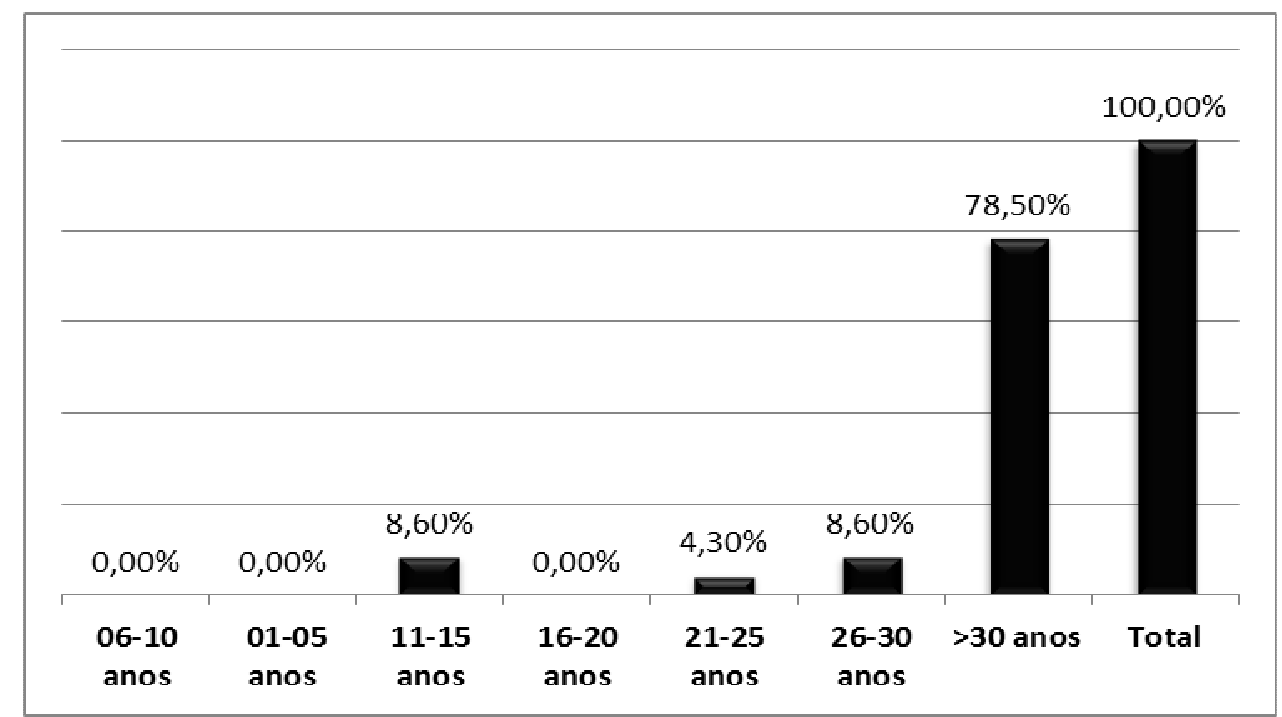

Gráfico 6: Tempo de trabalho com o tradicional ofício oleiro

Fonte: Elaboração dos autores.

A realização dos inquéritos permitiu-nos, por meio dos contatos, algumas impressões. Os indivíduos que disseram não receber nenhum apoio fazem parte dos projetos de divulgação dos órgãos públicos, mas o que foi percebido durante os trabalhos de campo é que não existem diálogos entre os dois segmentos para traçar as metas desejadas de divulgação, deixando os entrevistados com a sensação de abandono por parte dos gestores públicos.

Em termos gerais, $100 \%$ dos inquiridos disseram comercializar seus produtos em comércio próprio. Desse universo, $74,1 \%$ ainda expõem e comercializam seus artesanatos em feiras e eventos. Enquanto isso, 17,3\% dos sujeitos envolvidos com a olaria vendem seus produtos em postos de turismo da Entidade Regional de Turismo do Alentejo, e 8,6\% comercializam também no museu do Barro de Redondo, nas lojas de Lisboa e em residências. 
Assim, faz-se relevante, mediante o fator de promoção e divulgação, retornar à discussão sobre os meios utilizados: 56,6\% não fazem divulgação por nenhum meio de comunicação. Tal resultado não reflete a realidade, pois tais indivíduos são beneficiados pelos trabalhos midiáticos desenvolvidos nas Câmaras Municipais e na Entidade Regional de Turismo. Convém salientar que $43,4 \%$, disseram fazer divulgação por meio dos meios de comunicação existentes.

Tal fato nos faz considerar que, do total de inquiridos (100\%), 43,4\% que realizam divulgação disseram utilizar a internet (páginas de Facebook, e-mails, sites e blogs) como contexto de divulgação e promoção. Um aspecto em destaque, conforme os dados colhidos em campo, é o uso do site Facebook, tornando-se o mais citado pelos proprietários das olarias. Enquanto isso, $20 \%$ apontaram os usos de cartazes, folhetos, revistas e museu itinerante, colocando as peças em exposição. Outro fator relevante é que $10 \%$ dos inquiridos apresentaram o uso das emissoras de rádio, mas, segundo eles, não conseguem pagar pelos horários de televisão, devido à pequena margem de lucro dos comércios.

Durante a obtenção de dados no campo, solicitou-se aos oleiros inquiridos uma avaliação sobre o incentivo da Entidade Regional do Turismo às olarias do Alto Alentejo (Gráfico 7): 25,8\% avaliaram como ruim, pois, segundo eles, o órgão de turismo é sempre ausente e isso faz com que o Estado fique distante das atividades oleiras.

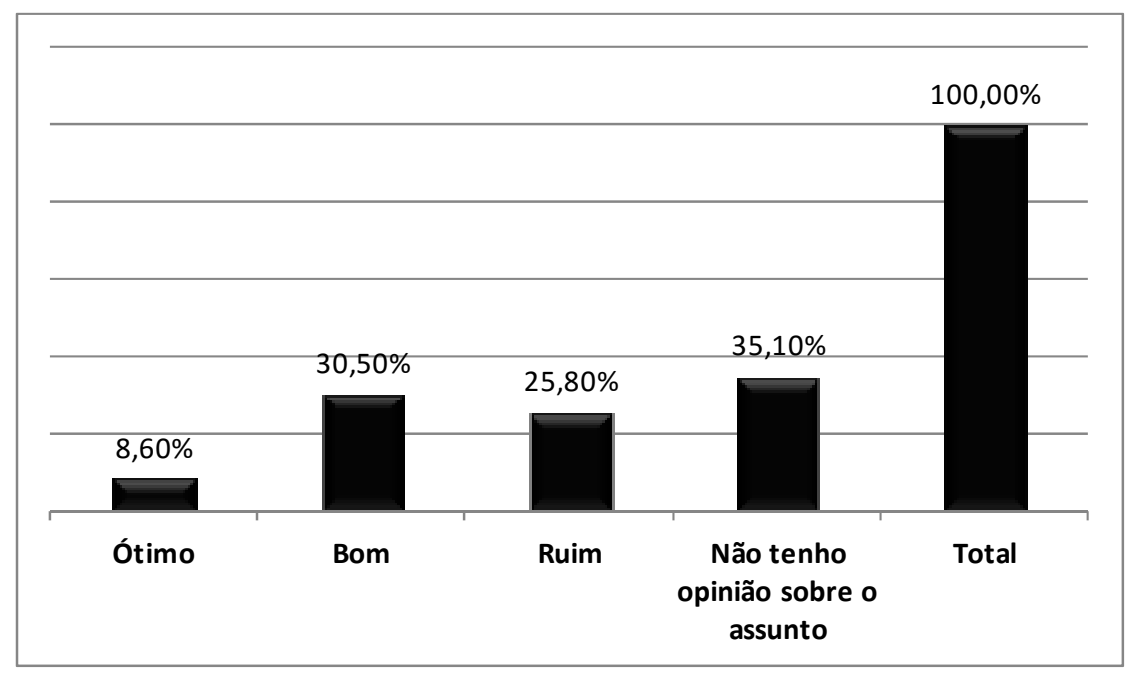

Gráfico 7: Apoio da Entidade Regional do Turismo

Fonte: Elaboração dos autores. 
Procurou-se também avaliar o trabalho das Câmaras Municipais (Gráfico 8). A maioria dos barristas alentejanos $(52,3 \%)$ avaliou-o como bom. De maneira surpreendente, a falta de opinião sobre o assunto teve índice bem abaixo dos dados apresentados no Gráfico 7. Nesses termos, os apoios recebidos nas divulgações e nas comercializações das peças de barro são contributos para salvaguardar o ofício oleiro de municípios e aldeias do Alto Alentejo.

A presença de oleiros e principalmente de suas peças em feiras de artesanato, exposições, museus e postos de turismo, para Martins (1987, p. 8), “[...] tem contribuído para valorizar os artífices de barro, cuja atividade passou a ser olhada com respeito e admiração". A peça é a imagem espontânea de territórios, paisagens e lugares, que surge de mãos criativas de oleiros sentados à roda, transformando barro em objetos de identidade e bens culturais, patrimônios que expressam uma singularidade e se tornam importantes instrumentos de promoção do turismo cultural regional.

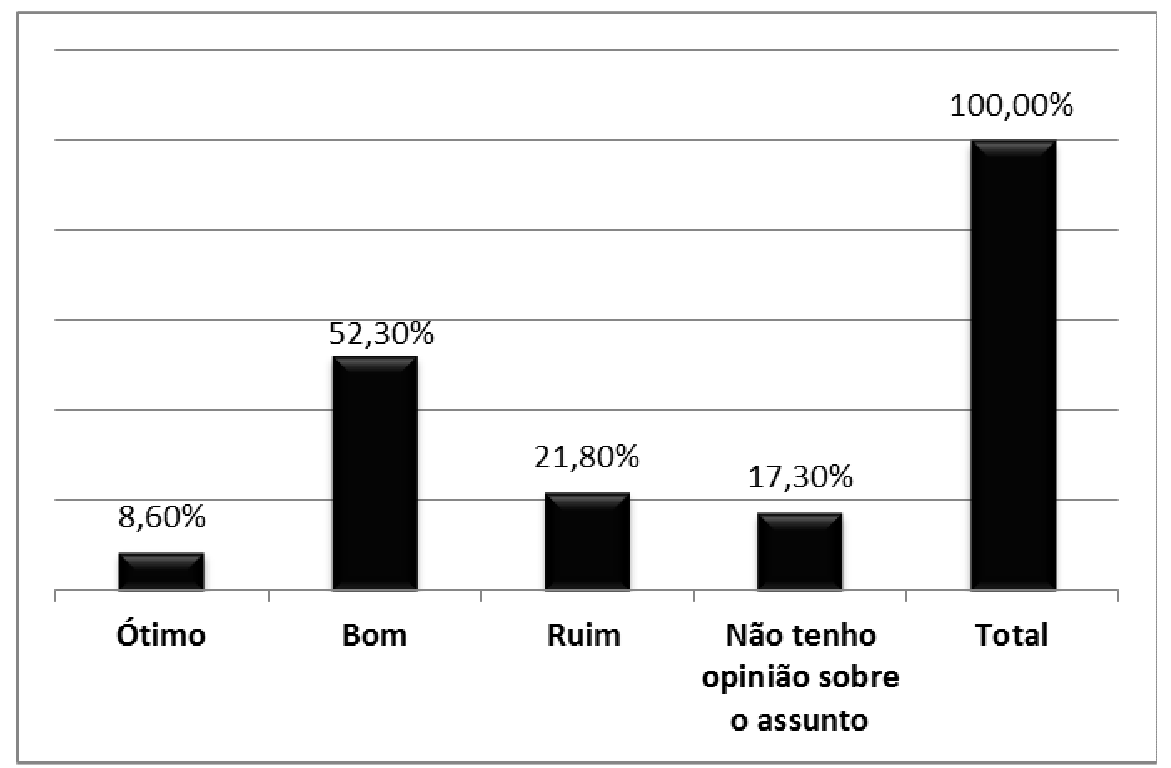

Gráfico 8: Apoio das Câmaras Municipais

Fonte: Elaboração dos autores.

Com base nos números apresentados, é relevante salientar que a cultura, incluindo especialmente a cultura oleira, é antes uma realidade de escala local:

[...] de um círculo de interação a outro, trocas têm lugar; equivalências se desenvolvem, de modo que a comunicação seja possível, porém nem tudo é transmitido. Não existe compreensão real dos processos culturais se negligenciamos o jogo da intersubjetividade (CLAVAL, 2006, p. 95). 
Com o foco na investigação em que se colocam em pauta as peças produzidas nessas olarias, buscou-se saber se elas se inserem na cultura, identidade e realidade local, destacando se tais objetos têm um caráter prático ou decorativo. Desse modo, 100\% dos inquiridos disseram que as peças feitas nas olarias são de caráter prático e decorativo, mas as decorativas são as mais comercializadas, o que viabiliza a existência dessa arte popular com o barro no contexto regional, municipal e local.

De forma geral, foram consideradas algumas questões básicas sobre a comercialização dos produtos: Como é realizada? Quem são os principais clientes? Todos (100\%) disseram que a comercialização tem se constituído na própria região, para turistas e moradores. Desses, 25,8\% afirmaram que também exportam para o exterior por meio de contatos feitos pela internet, e outros 60,8\% comercializam em outras regiões do país, sobretudo em Lisboa, Algarve, no Norte e em Açores.

Nesse contexto, almejou-se conhecer os países consumidores dos produtos das olarias do Alto Alentejo: 83,4\% dos inquiridos citaram os EUA e os países da União Europeia, como Inglaterra, Alemanha, França, Itália, Holanda, Bélgica, Grécia, Espanha e Noruega; enquanto isso, 33,2\% destacaram Brasil, Rússia, Japão e África do Sul. Para esses sujeitos, os consumidores desses países têm atribuído às peças de barro não somente um valor comercial, mas um sentido de valor ao patrimônio cultural local e regional.

Para finalizar a apresentação dos resultados do inquérito, é possível considerar que $100 \%$ dos sujeitos entrevistados não fazem parte de nenhuma associação de oleiros, o que mostra que eles não se comunicam e que não existem redes com essa intenção - tal empecilho é um forte agravante para a continuação e existência dessa tradição e identidade regional. Para tanto, é primordial que os oleiros se organizem de fato, potencializando a tradição e o trabalho popular com o barro.

\section{Presente, Perspectivas e Futuro Para a Olaria no Alto Alentejo}

Ao refletir sobre alguns aspectos relacionados ao futuro da olaria no Alto Alentejo, parecenos que dificilmente essa atividade manterá a tradição com uma vertente utilitária e rústica, apenas de consumo popular e de base local. Isso se deve ao fato de ela ter se transformado num trabalho artesanal, dirigido a um público que conhece a arte de mãos criativas e que 
busca peças de barro confeccionadas com qualidade técnica e artística, atendendo diferentes atores, mercados e, especialmente, o segmento turismo cultural.

Em um contexto geral, muitas oficinas que continuam com a produção de cerâmica realizaram investimentos de modernização, introduzindo o uso de equipamentos tecnológicos, como fornos elétricos, computadores e novas ferramentas de trabalho. Essas olarias têm abandonado a extração manual de argila e adquirido uma pasta de barro industrializada, que é comercializada na região por empresas de outras partes de Portugal e da Espanha. Essa realidade é enfatizada pela obra de Gancho (2000, p. 201-203) como um:

[...] tipo de pasta de origem externa muito plástica e fina de uma cor vermelha intenso, tem progressivamente vindo a ser usada, desde a década de 1980, para o fabrico, de louça intensamente decorada, por torneamento ou moldagem mecânica. [...] estas permitem um bom acabamento estético do produto.

Essa dinamização socioeconômica tem levado a uma diversificação da base produtiva, assentada também em melhores condições de trabalho e qualificação na infraestrutura das oficinas. No que concerne aos processos de fabricação tradicional e contemporânea de cerâmica alentejana, eles ainda coexistem, mas, em poucos anos ou até mesmo até a próxima década (2021), ter-se-á de modo geral o predomínio dos processos técnicos contemporâneos, com a forte presença da tecnologia e o uso de equipamentos mecanizados e de matérias-primas produzidas industrialmente, o que reduz o tempo de trabalho e o desgaste físico dos sujeitos artesãos.

Cada vez mais esses investimentos e transformações deverão prosseguir ao longo das primeiras décadas do século XXI. Todavia, eles serão baseados em ações desarticuladas e individualizadas dos atuais proprietários, sem mobilizar os diversos atores oleiros para um trabalho em rede que aglutine a vontade de estabelecer uma economia oleira sustentável, melhorando a qualidade de vida dessas populações.

É fundamental que as Câmaras Municipais do Alto Alentejo, em parceria com o governo de Portugal, retomem os projetos das Escolas-Oficinas de Artesanato com o barro que foi esquecido nos últimos anos. O ensino é uma prática social relevante no processo de formação e manutenção da cultura popular oleira regional, levando os interessados na barrística a experimentar um cotidiano impregnado de possibilidades econômicas.

Essas cidades pequenas, denominadas como centros oleiros, são museus vivos. É preciso preservá-los, mas infelizmente os critérios de "[...] atribuição de subsídios à cerâmica popular 
valorizam práticas de mecanização e industrialização, estando a contribuir para a rápida destruição de uma identidade cultural e património local” (GANCHO, 2000, p. 204), compreendida aqui como parte da cultura popular tradicional da região investigada.

As forças mais representativas dessas urbanidades, juntamente com a comunidade, precisam criar meios de identificar os obstáculos ao desenvolvimento do artesanato oleiro, dando autonomia a esse tradicional e popular ofício. Nas contradições entre o discurso e realidade, cabe também destacar os argumentos de Hernández (2013, p. 40): "La cultura y la política están presentes en el espacio y le dan vigor y dinámica al desenvolvimiento de las relaciones sociales en las que están inmersos los actores sociales". Nessa perspectiva, toma-se a leitura de que:

La política turística en los destinos turísticos debe intentar integrar en su estrategia tanto acciones de mitigación como de adaptación. La capacidad de un destino de llevar a cabo actuaciones enmarcadas en estas dos líneas estratégicas variarán según el destino y el tiempo (FAYOS-SOLÀ; JAFARI, 2009, p. 217).

Nesse contexto é preciso salientar o reconhecimento da Câmara Municipal de Estremoz. Ela iniciou, em abril de 2013, um processo de investigação, produção de conhecimento e angariação de apoios de personalidades e instituições, que tem por objetivo final a integração da Produção de Bonecos em Barro de Estremoz (Figura 5) na lista representativa de Patrimônio Cultural Imaterial da Humanidade da Organização das Nações Unidas para a Educação, a Ciência e a Cultura (UNESCO).

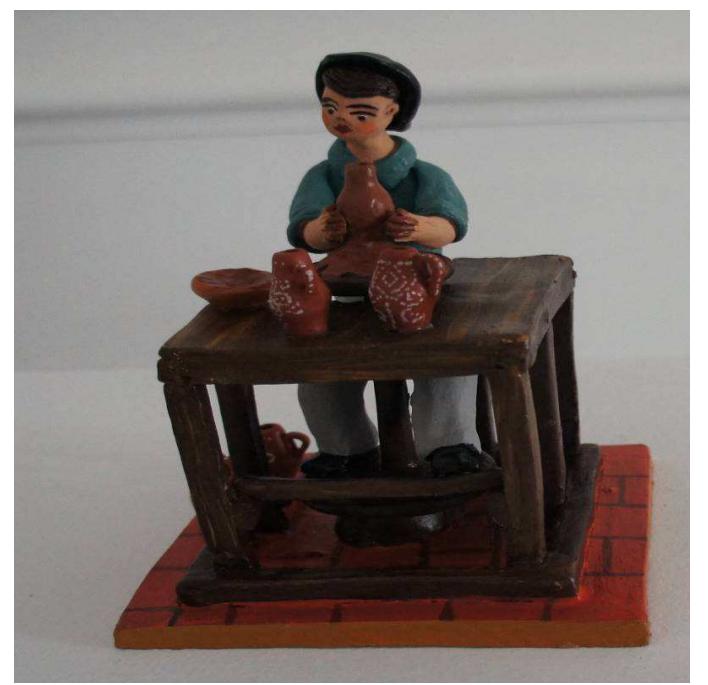

Figura 5: Boneco de Estremoz - representa o oleiro à roda construindo suas peças com as mãos. Fonte: Elaboração dos autores. 
Como primeiro passo para a conclusão deste objetivo, no mês de março de 2014 foi entregue o pedido de inventariação. Esse reconhecimento vai promover um Plano de Salvaguarda do Boneco de Estremoz, dando visibilidade aos artesãos e à arte, além de chamar a atenção de jovens para a barrística e promover, a nível internacional, uma arte popular tão emblemática. Essa consideração mostra que as "[...] formas particulares de cultura se relacionam com especificidades de tempo e de lugar que devem ser tidas em conta" (SANTOS, 2006, p. 143).

A realidade do turismo cultural oleiro do Alto Alentejo apresenta inúmeras fragilidades e é incapaz de responder equilibradamente aos desafios das primeiras décadas do século XXI, pois ainda falta uma associação que englobe tais sujeito. Não existem redes visando construir novos tipos de relações e novas formas de atuação no mercado, sendo que as ações ocorrem de forma individualizada e sem obediência a uma estratégia ou a uma ideia comum dos órgãos de turismo presentes na região.

Em consequência, apesar de ainda existir em territórios, lugares e paisagens alentejanas, a arte oleira perde sistematicamente posição no desenvolvimento do turismo regional ou se coloca como lógica complementar à medida que suas ações ocorrem de forma individualizada pelos sujeitos que desenvolvem esse ofício - o que se verifica é uma posição periférica diante de outros setores econômicos prioritários, como a hotelaria e a restauração. Assim, é fundamental avaliar a modalidade do turismo praticado para perceber que:

The natural and cultural environment has intrinsic value, and is protection and preservation is essential to the long-term success and viability of tourism. The relationship between tourism and the environment, both natural and cultural, must be managed so that it is sustainable in the long-term. [...] Tourism should communicate appropriate cultural and environmental sensitivity. Local involvement in sustainable tourism planning processes is essential in promoting harmony between tourism and the residents (HOVINEN, 2006, p. 80-81).

Entretanto, tais paisagens, em razão das diversidades de formas visíveis ou pelas diferentes maneiras de vê-las, vivê-las e aprendê-las, principalmente pelo olhar do visitante, turista ou morador, colocam em si uma potencialidade e atratividade que possibilita várias formas de contribuir com o desenvolvimento do destino. Para que isso ocorra, são primordiais as ações conjuntas de oleiros sensibilizados, em parceria com os atores públicos e privados regionais. 


\section{Considerações Finais}

O tema abordado ainda não tem suscitado o interesse geral e tem passado despercebido no

debate científico. É, de fato, uma questão importante na abordagem do turismo cultural, pois o público precisa conhecer não apenas as peças artesanais e exclusivas, mas os artistas que as fazem. Compreender o ofício oleiro na vertente do destino turístico é uma forma de conhecer de perto quem fez o produto, como o fez, que técnica usou e como é o processo de criação de cada peça - é como se cada artista contasse o segredo de sua criação por meio da construção do trabalho científico.

A cerâmica do Alto Alentejo é uma produção artística de caráter popular com tipologias tradicionais que estão a desaparecer. Apesar dessa realidade e da redução do número de artesãos, os concelhos e a aldeia aqui estudados mantêm sua capacidade produtiva e, por tradição cultural, ainda produzem uma diversidade de louças, bonecos, cerâmicas de construção, de armazenamentos e lúdicas, bem como outras formas, peças que são identidades dos circuitos urbanos fortificados, do seu povo e de uma região que também é turística.

A olaria, ao assumir seu papel, ultrapassa largamente tempos e paisagens. É uma marca regional tão importante que dá nome ao vinho alentejano tinto lançado na primeira década do século XXI pela Cooperativa Agrícola de Reguengos de Monsaraz, uma homenagem dos empresários locais à tradicional atividade que se mantém e dá identidade às diferentes paisagens do Alto Alentejo.

É certo que os concelhos investigados têm desenvolvido ações positivas, como a criação de museus em Redondo e Estremoz, além da realização de feiras, eventos e exposições, quase sempre no âmbito de atividades ligadas ao turismo cultural, mas sem uma estratégia de envolvimento maciço dos oleiros regionais, deixando de produzir profundas inter-relações com a comunidade em geral. Portanto, faz-se necessário atingir uma dimensão na perspectiva de envolvimento de todos os interessados.

Nesse âmbito, a fim de aprofundar e não concluir a reflexão geral sobre a arte oleira alentejana, é inegável que esse ofício desempenha um papel fundamental na consolidação da região como destino turístico cultural, dando consistência à movimentação de pessoas que buscam especificidades, particularidades, identidades e patrimônios dos territórios visitados. Ao mesmo tempo, a barrística funciona como instrumento de reequilíbrio econômico e social, 
pois é uma fonte geradora de renda para essas localidades com suas muralhas e igrejas católicas, aproximando a atividade turística da história e tradição dos lugares.

\section{Referências}

BARRETTO, Margarita. Cultura e turismo: discussões contemporâneas. Campinas: Papirus, 2007.

BORRALHO, Álvaro António Gancho. As artes do barro: contribuições para o estudo dos bonecos de Estremoz. 1993. Dissertação (Tese de Licenciatura em Sociologia, vertente de Sociologia da Cultura) - Programa de Pós-graduação do Instituto Superior de Ciências do Trabalho e da Empresa, do Instituto Universitário de Lisboa, Lisboa, 1993.

CLAVAL, Paul. Abordagens da Geografia Cultural. In: CASTRO, Iná Elias de; GOMES, Paulo Cesar da Costa; CORRÊA, Roberto Lobato (Orgs.). Explorações geográficas: percursos no fim do século. Rio de Janeiro: Bertrand Brasil, 2006.

CLAVAL, Paul. Geografia e dimensão espacial: a importância dos processos na superfície da terra. In: ALMEIDA, Maria Geralda de; CHAVEIRO, Eguimar F.; BRAGA, Helaine C. (Orgs.). Geografia e cultura: os lugares da vida e a vida dos lugares. Goiânia: Vieira, 2008.

CONDE, Antónia Fialho. Mãos que criam - a olaria em São Pedro do Corval. Reguengos de Mosaraz: Papel \& Tinta, 2013.

COSTA, Carlos; BRANDÃO, Felipa; COSTA, Rui; BREDA, Zélia. Turismo nos países lusófonos: conhecimento, estratégia e territórios. Lisboa: Escolar, 2014.

CUNHA, Licínio. Introdução ao turismo. Lisboa: Verbo, 2001.

FAYOS-SOLÀ, Eduardo; JAFARI, Jafar. Cambio climático y turismo: realidade y ficción. Valência: Publicacions de la Universitat de Valência, 2009.

GANCHO, Luísa Margarida Palma Coelho. O centro oleiro de Redondo (1998/2000): contributo para o estudo do seu sistema técnico de produção cerâmica. 244 f. 2000. Dissertação (Mestrado em Estudos Portugueses) - Programa de Pós-graduação da Faculdade de Ciências Sociais e Humanas, da Universidade de Lisboa, Lisboa, 2000.

HERNÁNDEZ, Luis Llanos. Territorio y apropriación del espacio social en las tierras indias de Chiapas: rupturas y continuidades en los precesos de cambio social. Ciudad de México: Plaza y Valdez, 2013.

HOVINEN, Gary R. Lancaster County, the TALC, and the search of sustainable tourism. In: BUTLER, Richard W. Aspects of tourism - the tourism area life cycle: applications and modifications. Clevedon: Channel View, 2006. (v. 1.).

INSTITUTO DO EMPREGO E FORMAÇÃO PROFISSIONAL/DELEGAÇÃO REGIONAL DO ALENTEJO. Artesanato da região Alentejo. Évora: Norprint, 2000.

LEPIERRE, Charles. Estudo químico e tecnológico sobre a cerâmica portuguesa moderna. 2. ed. Lisboa: TECCT, 1912.

MARTINS, Rui de Souza. Projecto de musealização de uma olaria de Vila Franca do Campo. Museu Municipal de Vila Franca do Campo, 1988. Separata de Arquipélago. Revista da Universidade dos Açores, Ponta Delgada, n. 2, p. 3-40, 1987.

MAUSS, Marcel. Manual de etnografia. Porto: Pórtico, 1972.

MEDINA, N.; SANTAMARINA, J. Turismo de naturaleza en Cuba. Havana: Unión, 2004. 
MENDES, Júlio da Costa; SILVA, João Albino; FERREIRA, Pedro Lopes. Quality assessment of Portuguese destinations. In: SILVA, João Albino; JAFARI, Jafar; SCOTT, Noel. Tourism development and management: challenges and opportunities for Algarve, Portugal. Aveiro: Rainho \& Neves, 2010.

MINISTÉRIO DA ECONOMIA. Turismo em Portugal: política, estratégia e instrumentos de intervenção. Lisboa: Direcção Geral do Turismo, 2002.

NUNO, Carlos Simões/CÂMARA MUNICIPAL DE ALMADA. Olaria tradicional portuguesa. Almieira: Greca, 2002.

PARVAUX, Solange. La céramique populaire du haut-Alentejo. Paris: Presses Universitaire de France, 1968.

RIBEIRO, Orlando. Portugal - o Mediterrâneo e o Atlântico. 4. ed. Lisboa: Sá da Costa, 1986.

SANTOS, Maria da Graça Mouga Poças. Espiritualidade, turismo e território. Estoril: Principia, 2006.

VERA, J. Fernando; PALOMEQUE, F. Lópes; MARCHENA, Manuel J.; ANFON, Salvador. Análisis territorial del turismo. Barcelona: Ariel, 1997.

Recebido em: 06/04/2015

Aprovado em: 08/11/2015 